magmatic water contribution in the initial weeks following the eruption.

Finally, an additional surprise in the days immediately following the 1991 eruption was the extraordinary abundance of bacteria in the water column and in thick mats on the sea floor, possibly supported by extremely high concentrations of $\mathrm{H}_{2} \mathrm{~S}$ in the vapour-rich vents. Yet, by
1993, the thick accumulations of bacteria were gone, and macrofaunal assemblages had redeveloped ${ }^{14}$. Clearly, geophysicists, geochemists and biologists need to work together closely to understand the effects of discrete eruptive and tectonic events on global heat and geochemical budgets, and on sea-floor biodiversity. Interdisciplinary efforts aimed at rapid response to volcanic eruptions, time-series monitoring and setting up ocean-floor observatories are paying big dividends in understanding these dynamic and complex processes ${ }^{4,9,15-17}$.

Wayne C. Shanks is at the US Geological Survey Branch of Geochemistry, Box 25046, Denver, Colorado 80225, USA.

\title{
Harold M. Weintraub (1945-95)
}

I FIRST met Harold Weintraub, who died on 28 March, in 1971. As a 25-year-old MD/PhD student working with Howard Holtzer at the University of Pennsylvania, he came to visit my new laboratory in Princeton to investigate taking a postdoctoral position with me. He had been studying how cells make the decision to differentiate and was intrigued by hints that DNA replication might facilitate the permanent changes in gene expression that determine cell fate. Hal wisely decided to do his post-doctoral work with Sydney Brenner and Francis Crick in England, but he had made such a powerful impression that we quickly recruited him back to Princeton as an assistant professor in 1973.

Hal Weintraub was to remain obsessed with the question of how cells change from one state of determination to another during embryonic development for his entire scientific career. Initially he focused on the intriguing (and still uncertain) idea that the histones, and the chromatin structures that they form, play a central part in the uniquely stable changes in gene expression that occur as eukaryotic cells differentiate. A fearless experimentalist, he probed the structure of chromatin with all of the tools he could imagine - chemicals, proteases and nucleases, in all combinations. With his post-doctoral fellow, Mark Groudine (later a long-term colleague and close friend), he discovered that the globin gene becomes 'open', as judged by its susceptibility to digestion by pancreatic DNase I, long before it is actually expressed in immature red blood cells. The mechanisms involved are fascinating and are still under investigation in many laboratories.

Hal seemed to be born to do science. I remember walking into his empty shell of a laboratory the week after he arrived in Princeton: somehow he had already managed to borrow enough glassware and reagents to begin a major experiment. Highly innovative, his interest and ener. gies were infectious. Soon he had most of the other assistant professors at Prince. ton (including myself) thinking about how embryos develop. Through journal clubs, evening special topics courses and seminars, we worked ourselves into a frenzy of excitement thinking about the molecu. lar mechanisms that cells might have developed to make multicellular life possible. Hal's influence probably explains why Marc Kirschner, Abe Worcel, Uli Laemmli and I - all of whom arrived

\section{IMAGE UNAVAILABLE FOR COPYRIGHT REASONS}

Hal Weintraub - love for science.

at Princeton with little or no background for this problem - started working on some aspect of the molecular biology of embryonic development within a few years.

Throughout his career, Hal kept his focus on the central biological problem of how cells in embryos change their patterns of gene expression in highly organized ways. He left Princeton in 1978 and moved to what was then a relatively obscure research laboratory where he could spend more time doing experiments himself. Attracted by his presence, many of the country's most promising young scientists would soon join him there; as a result, the Fred Hutchinson Cancer Research Center in Seattle quickly became one of the world's most exciting biological research centres. Its tremendously successful coalition of small, highly interactive laboratories is based on Hal's insistence that laboratory leaders should have the time to do experiments themselves. In this and other ways, he produced a model collegial environment.

From this laboratory there eventually came two marvellous discoveries. First there was the demonstration that the introduction of antisense RNA molecules into cells could shut down the expression of specific genes, providing a powerful new tool for the dissection of cell function. A few years later, a novel search strategy for a master gene regulatory protein involved in muscle development culminated in the discovery of MyoD, a DNA-binding protein that can $\overline{\overline{0}}$ convert a variety of other cell types into myoblasts, as well as boost its own synthesis to provide the type of cell memory required to explain the stability of cell determination events. The discovery of MyoD altered the way we think about the changes in gene expression that occur dur. ing embryonic development, the very same problem that had obsessed $\mathrm{Hal}$ since his days as a graduate student.

Everyone who knew Hal will recognize that what I have written thus far is inadequate to describe his quality. He inspired many young scientists. Perhaps most remarkably, his whole life consisted of a search for novel and interesting ideas, and he derived at least as much joy from those of others as he did from exploring his own. My last visit with him was typical: although he had been diagnosed with an incurable brain tumour in September 1994, Hal continued to concentrate on science until his death. During a threehour breakfast in December, we marvelled at the complexity of cell signalling networks, at the way that cells have made microswitches out of proteins and at the whole range of ingenious mechanisms that make life possible. His face was aglow with the warm smile that typified this unassuming man; his love for science seemingly had allowed him to forget his impending mortality.

Scientists like Harold Weintraub are rare, and his death leaves an empty space in our community. Bruce Alberts

Bruce Alberts is currently President of the National Academy of Sciences, 2101 Constitution Avenue NW, Washington DC 20148, USA. 